although the systems of health care and social services differ. Between 1977 and 1987 the number of hospital residents in the UK fell by $30 \%$ from 84,000 to 60,000 , while at the same time the number of residential places in the community increased by only 4,000 places (Department of Health, 1989). Homelessness has increased dramatically. Ex-patients in jail or who were homeless could not receive a managed service.

Political disagreements between many inner city local authorities and central government have lead to funding crises. In America this conflict was between federal and state government, whereas in Britain it is between central and local government. Both conflicts produce the same result for the consumer-fragmented services. The current fear among those implementing Caring for People is that community care policies are really concerned with reducing central government expenditure. Clearly there are parallels between the fragmentation of services identified by RWJF and in our own system.

The RWJF approach offers a way of working which is an alternative to fragmentation. The starting point is that change is to be welcomed and coordination of effect is a key aspect of service planning and delivery. Such an approach is based on principles, it is not prescriptive, nor driven by any single discipline or ideology. Local cooperation and good practice take the place of single answer solution to complex problems.

The current changes in mental health services are exciting because they are moving away from a sole concern with detained patients to care in patients own communities. The RWJF principles do not have to be restricted to America - the opportunity is here for the taking.

\section{Conclusions}

The RWJF process assumes that if enthusiasts are found, and supported financially and managerially, a new type of service can be developed, which is desirable to clients and providers, and is cost effective. Many of the components identifiable in these projects are also to be found in this country; what is so often missing in Britain is the opportunity to realise this potential. Central to the RWJF approach is the notion that choices should be real for patients and professionals alike. To achieve successful systems change means identifying opinion formers in the community and in the services, and harnessing their energies. Finally, it seems that in Britain it has taken time to learn the lesson that quality of service is not an optional extra, and neither is evaluation of new service provision.

\section{References}

AIKEN, L. H. (1987) Unmet needs for the chronically mentally ill: will nursing respond? IMAGE: Journal of Nursing Scholarship, 19, 121-125.

Department of Health (1989) Personal social services: provision for mentally ill people in England 1977-1987. Statistical Bulletin, 3,89.

Goldman, H., Adams, N. H. \& Taube, C. A. (1983) Deinstitutionalisation: the data demythologised. Hospital and Community Psychiatry, 34, 129-134.

- \& MORRISSEY, J. P. (1985) The alchemy of mental health policy: homelessness and the fourth cycle of reform. American Journal of Public Health, 75, 727-731.

Griffiths, R. (1988) Community Care: An Agenda for Action. London: HMSO.

STEIN, L. A. \& TEST, M. A. (1980) Alternatives to mental hospital treatment. Archives of General Psychiatry, 37, 392-397.

\title{
Members fluent in European languages
}

The College is focusing increasingly on the development of its links with other European countries and is keen to recruit the help of Members with expertise in European languages. Any Members who are fluent in a European language and who would be prepared to help us communicate with other psychiatric organis- ations are asked to contact me as soon as possible. I envisage that this commitment would be light; probably involving translating some correspondence and occasional scientific papers.

Dr Fiona Caldicott 